\title{
Experimental research on hydraulics of flood discharge tunnel and improving schemes for choking
}

\author{
Mingxiao LIU ${ }^{1}$, Guodong LI ${ }^{1}$, Michele GUALA², Dongpo SUN ${ }^{3}$ \\ 1. State Key Laboratory Base of Eco-hydraulic Engineering in Arid Area, Xi'an University of Technology, Xi'an, China, \\ elinunu@163.com,gdli2010@yeah.net \\ 2. St. Anthony Falls Laboratory, Department of Civil, Environmental and Geo-Engineering, College of Science and Engineering, University of \\ Minnesota, Minnesota, United States, mguala@umn.edu \\ 3. North China University of Water Resources and Electric Power, Zhengzhou, China, sundongpo@ncwu.edu.cn
}

\begin{abstract}
Due to the wide range of water levels in reservoir operation, the hydraulic functionality of free surface tunnels in supercritical flow conditions, while discharging beyond design conditions, deserve further studies. To investigate the safe discharging of low drop tunnels, a scale model of a spillway system was built and tested under different flow conditions and structural configurations. Water depth, velocity and flow regime in tunnel and flip bucket reach were measured in experiments. In emptying reservoir operations, a surprising phenomenon was observed; specifically, at low discharges, supercritical flow occurred inside the tunnel while subcritical flow characterized the exit section, with a hydraulic jump forming and moving back into tunnel, forcing it to work under pressure. Critical discharge conditions below which hydraulic jump occurs in the tunnel is theoretically derived by $1 \mathrm{D}$ hydraulic analytical computation and experimentally confirmed as $\mathrm{q}_{\mathrm{c}}=0.485 \mathrm{q}_{\mathrm{d}}$. To eliminate risk of choked tunnel, a modification is envisioned by setting a torsion angle and a side-weir along the flip bucket section. Experiment results indicate that the combination of a skewed flip bucket and side weir can effectively decrease the outlet water depth, and mitigate the hydraulic jump, avoiding tunnel choking thanks to redirecting the flow into the side weir and to centrifugal force effects. Ski jump flow through the skewed flip bucket and the downstream river regime were also improved.
\end{abstract}

Key-words: physical model, hydraulic jump, skewed flip bucket, spillway tunnel, reservoir

\section{Recherches expérimentales sur l'hydraulique d'un tunnel d'inondation et sur l'amélioration des régimes d'obstruction}

\begin{abstract}
RÉSUMÉ. - En raison de la vaste gamme de niveaux d'eau dans l'opération de réservoir, l'hydraulique des tunnels à surface libre dans des conditions d'écoulement supercritique, au-delà des conditions normales de fonctionnement, méritent de plus amples études. Pour étudier le débit de tunnels de faible chute, une maquette d'un système de déversoir a été construite et testée dans des conditions d'écoulements et de configurations structurelles. La hauteur d'eau et la vitesse dans le tunnel et dans la section de déflection ont été mesurées au court des expériences. Dans les opérations de vidange du réservoir, un phénomène surprenant a été observé ; à faible débit un écoulement supercritique s'est produit à l'intérieur du tunnel alors qu'un écoulement sous-critique est apparu dans la section de sortie avec la formation d'un ressaut hydraulique remontant dans le tunnel. Les conditions critique d'écoulement en dessous desquelles un ressaut hydraulique dans le tunnel est décrit par une solution analytique $1 \mathrm{D}$ et confirmée expérimentalement par $\mathrm{q}_{\mathrm{c}}=0.485 \mathrm{q}_{\mathrm{d}}$. Pour éliminer les risques d'obstruction du tunnel, une modification de la section de sortie est proposée. Les résultats expérimentaux montrent que la solution proposée tend à réduire la hauteur d'eau en sortie, limite le ressaut hydraulique, et évite l'obstruction du tunnel grâce à une déviation de l'écoulement dans le déversoir et les effets de la force centrifuge.
\end{abstract}

Mots-clés : Modèle physique, ressaut hydraulique, section de déflection, déversoir, réservoir

\section{INTRODUCTION}

Spillway tunnels are a common and effective structure for releasing flood from reservoir. They are mainly designed as partially-full flowing tunnels in which the flow is described as an open channel supercritical flow. Comparing with other types of tunnel, its discharge capacity is largest and the size of the cross section is smallest, which means that the engineering cost is minimal. The section size of the tunnel depends on the hydraulic factors defined for the design flood condition. Therefore, normally, the headroom ratio of the tunnel could meet the safety requirement of discharging flood under design flood condition (avoiding the full flowing, in pressure). However, to control the reservoir water level before rain season or to desilt the reservoir deposition, the tunnel is used to adjust water levels in a wide range of operating conditions. During the transient periods, the safety and stability of the tunnel deserves careful attention, in particular while discharging flood outside the design conditions [Leutheusser and Kartha, 1972; Ma et al., 2012].

The free surface tunnel flow generally has the following characteristics: high velocity, great variation of water head, and varying operating conditions. A significant difference between inlet and outlet heads in the free surface tunnel and in the flip bucket is necessary to ensure a large enough velocity and discharge. However, due to the limitation of the 
boundary conditions, the drop in some spillway tunnels may be quite small, and the elevation of the flip bucket outlet is even higher than the inlet bottom elevation of tunnel. Under the design discharging condition, the flow in the tunnel is normally supercritical with high velocity, which provides enough momentum to generate a water nappe at the Ogee section and sustain a ski jump outflow over the flip bucket [Juon and Hager 2000; Heller, et al., 2005]. In such conditions, the headroom ratio in the tunnel typically meets the regulatory safe requirement.

However, for the free-surface tunnel with low drop, a dangerous flow phenomenon may occur during the flood discharging and reservoir emptying operations. When the reservoirs water level is lower and the discharge is smaller than the critical value, a hydraulic jump may occur in the outlet flip bucket section and may develop backward into the tunnel. Thus, the backwater in the outlet of the flip bucket section may result in a subcritical flow while the upstream flow in the tunnel is still supercritical, which causes the hydraulic jump to occur upstream of the outlet section.

Due to the sharp increase of the depth after the hydraulic jump, there is not enough headroom for the subcritical flow in the tunnel, and choking may occur. The hydraulic jump, which is one of the most common energy dissipation forms in open channel flows, will have a detrimental impact when it occurs in the tunnel. The emergence of the hydraulic jump will weaken the discharge capacity of the tunnel; more importantly, the depth after the hydraulic jump always exceeds the headroom ratio regulatory requirement to avoid the in-pressure tunnel regime, which poses serious safety risk to the reservoir discharging operations. Consequently, it is necessary to analyze the mechanism of hydraulic jump formation and its spatial evolution in the tunnel, and take proper engineering measures to eliminate its adverse effect when the hydraulic jump occurs without satisfying the safe discharging conditions.

Many researchers mainly focused on the tunnel discharging at design flood water level [Fan, 2009], however, little referred to the tunnel safety while discharging operation at a low water level [Sun et al., 2013]. Some scholars investigated the hydraulic jump in the sewer overflow tunnel system of a city by numerical simulation [Politano, 2007], and measured the hydraulic jump in experiment with singlecamera particle image velocimetry [Lennon and Hill, 2006]. On the properties of turbulence and energy dissipation in the hydraulic jump, theoretical analysis and laboratory investigations have been recently proposed [Jan and Chang, 2009; Wright, 2010]. But the problem that hydraulic jump forming with slightly supercritical Froude numbers, Fr, may choke the tunnel has not yet been extensively addressed [Chanson, 2011; Wu et al., 2014].

Based on a project case of a spillway tunnel in the reservoir of a pumped storage power station, experiments on a hydraulic model are conducted to study the hydraulic properties in the tunnel during discharging operation, especially under transient conditions. Comprehensive modifications to the deflecting flow sections are proposed, which could not only solve the problems caused by the hydraulic jump in the tunnel, but also protect the downstream dikes from scouring. Research findings may provide important value to the study of hydraulic jumps in general as well as site-specific solutions for undesired effects during transient hydraulic operations.

\section{CASE STUDY AND METHODOLOGY}

\section{II.1. Project description and focus issues}

The hydro-structure in a lower reservoir of the pumped storage power station is mainly composed of barrage, spillway and spillway tunnel (power station structure is not included). The capacity below the normal pool level is $5.961 \times 10^{7} \mathrm{~m}^{3}$, regulating storage is $4.148 \times 10^{7} \mathrm{~m}^{3}$. The designing flood and the checking flood standard for the discharging structure are based on the 200-year return's period flood and 2000-year return's period flood respectively. The designing flood level is $1061 \mathrm{~m}$, the checking flood level is $1063.67 \mathrm{~m}$, and the dead water level is $1042 \mathrm{~m}$. The spillway tunnel is $282.18 \mathrm{~m}$ long, its profile and local top view are shown in Fig. 1.

\section{II.2. Methodology}

To investigate the hydraulic regimes in the spillway tunnel, an undistorted hydraulic model is adopted to conduct

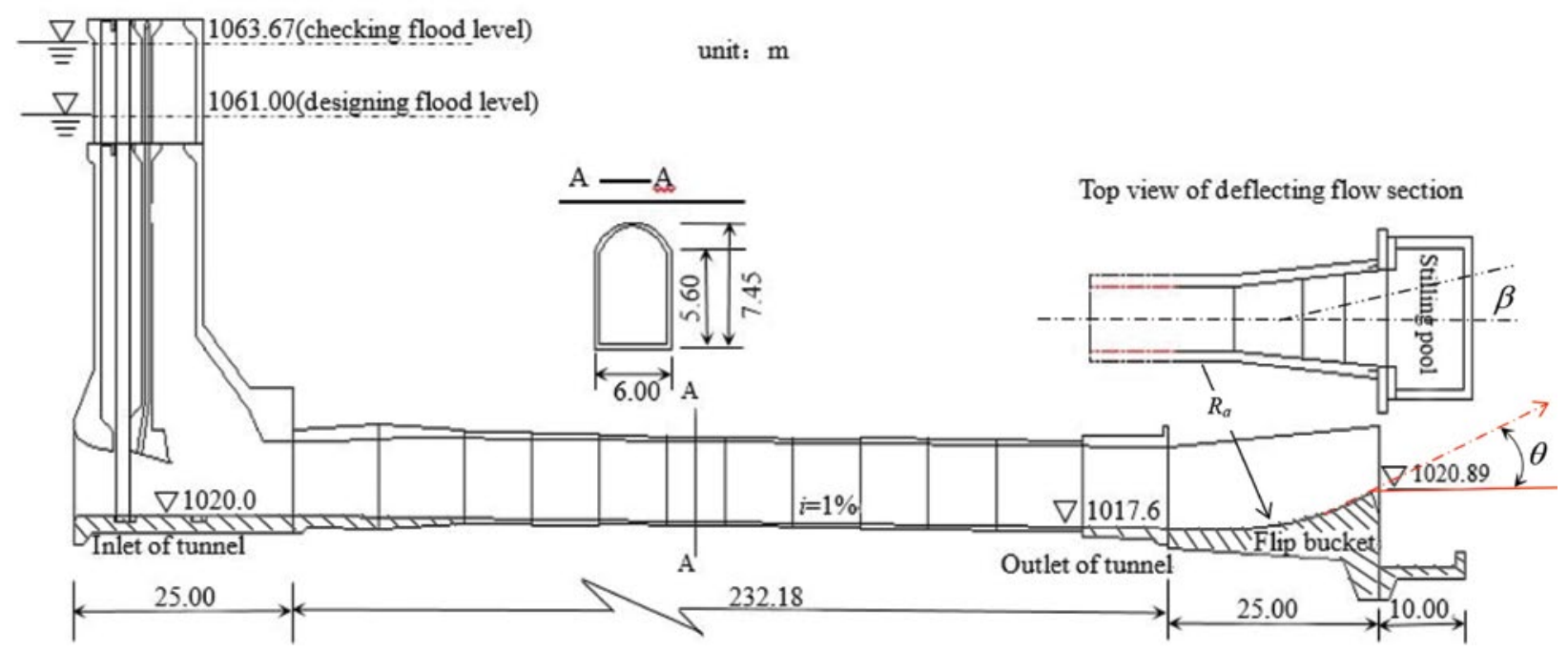

Figure 1 : Longitudinal profile of the tunnel and top view of the deflecting flow section (flip bucket). The location and the structural components of the tunnel are shown. The cross section size of the tunnel, the form of the deflecting flow section at tunnel exit and the typical flood levels are included. 
experimental tests. Because the major force acting on the flow is gravity, "gravity similarity criterion", or Froude similarity, is adopted in the model design. Geometry scale and velocity scale are shown in Table 1 . The Reynolds number $\left(\operatorname{Re}=\frac{4 R U}{v}\right)$ [USACE. WES, 1977] range is $0.74^{\prime} 10^{8} \sim 2.33^{\prime} 10^{8}$ for the prototype and $1.92^{\prime} 10^{5} \sim 6.1^{\prime} 10^{5}$ for the model. However, while the prototype flow is in the fully rough turbulent regime, the model flow is in the transitional regime, according to the curve of "resistance coefficients of open channel flow" (Hydraulic Design Chart 631) proposed by U. S. Army Engineer Waterways Experiment Station, Corps of Engineers [USACE. WES, 1977] and Chow [1959]. Yalin (1971) indicated that, if the prototype flow is in the rough turbulent regime and the model flow is in the transitional regime, one can still use the scale relations for the flow resistant force similarity corresponding to the fully rough turbulent flow, accepting a $12 \%$ deviation in the rough wall constant. Acknowledging the above limitation at the model scale, we base our formulation on the Manning-Strickler coefficient and on the fully rough turbulent regime that is unambiguously characterizing the flow at the prototype scale.

Table 1 : Model scaling

\begin{tabular}{cc}
\hline Control scale & Calculated value \\
\hline Geometry scale & $\lambda_{l}=55$ \\
Velocity scale & $\lambda_{\mathrm{v}}=\lambda_{l}^{1 /}$ \\
Roughness coefficient scale & $\lambda_{n}=\lambda_{l}^{1 / 6}=1.95$ \\
\hline
\end{tabular}

The friction force $T$, i.e., the resistant force at the channel bed due to roughness, can be expressed as follows [Yalin, 1971].

$$
T=\tau_{0} \chi L=\rho g J A L
$$

Where, $\tau_{0}$ denotes the shear stress on the bed, $L$ is the length of flow reach and $\chi$ is the wetted perimeter. $J$ is the energy slope and $A$ denotes the area of cross section.

In order to satisfy the flow resistant force similarity, the following criterion must be imposed:

$$
\frac{T_{\mathrm{p}}}{T_{\mathrm{m}}}=\frac{F_{\mathrm{p}}}{F_{\mathrm{m}}}
$$

Here, $F$ denotes the inertial force. The subscript " $p$ " denotes the prototype. The subscript " $m$ " denotes the model. Combining Equations (1) and (2) we obtain the following scaling equation:

$$
\frac{\lambda_{v}^{2}}{\lambda_{g} \lambda_{L} \lambda_{J}}=1
$$

Where, $\lambda_{v}, \lambda_{\mathrm{g}}, \lambda_{\mathrm{L}}, \lambda_{\mathrm{J}}$ denote the scaling factors for velocity, gravity, geometry and energy slope respectively. Based on the Froude number, $F r=\frac{v}{\sqrt{g h}}$, equation (3) is
translated into equation (4)

$$
\frac{F r_{p}}{J_{p}}=\frac{F r_{m}}{J_{m}}
$$

To achieve "turbulent resistant similarity", $J_{\mathrm{p}}=J_{\mathrm{m}}$ must be imposed, in addition to satisfying the "Froude similarity" $\left(F r_{\mathrm{p}}=F r_{\mathrm{m}}\right)$. As a result of this, by forcing $J_{\mathrm{p}}=J_{\mathrm{m}}$ and employing the Chezy formula, we obtain

$$
\frac{v_{p}^{2}}{C_{p}^{2} R_{p}}=\frac{v_{m}^{2}}{C_{m}^{2} R_{m}} \text { or } \frac{\lambda_{\mathrm{v}}^{2}}{\lambda_{C}^{2} \lambda_{R}}=1
$$

Where, $C$ denotes the Chezy coefficient and $R$ is hydraulic radius. According to Froude similarity, $\lambda_{\mathrm{v}}^{2}=\lambda_{L}$ and $\lambda_{\mathrm{R}}=\lambda_{L}$, implying that the formula above could be given as

$$
\lambda_{\mathrm{C}}^{2}=1 \text { or } C_{p}=C_{m}
$$

So, the Chezy coefficient $C$ can be obtained approximately by the Manning Formula $C=\frac{1}{\mathrm{n}} R^{1 / 6}$ (strictly valid at the prototype scale, which is in the fully rough regime), where $n$ denotes the roughness coefficient, leading to:

$$
\lambda_{C}=\frac{1}{\lambda_{\mathrm{n}}} \lambda_{R}^{1 / 6}=1 \text { or } \lambda_{n}=\lambda_{L}^{1 / 6}
$$

This implies that, when the flow is fully turbulent, "turbulent resistant similarity" is governed by the roughness coefficient scale (7). This is the method for designing the model roughness coefficient used in the paper, and shown in Table 1. In general, the roughness coefficient of a material is easy to get from the literature or by experimental investigation. The error of the model is less than $1.5 \%$ when designing the model resistance scale by adopting the formulas corresponding to the flow in the rough turbulent regime. The tunnel model is therefore made of transparent polymethyl methacrylate ( $n=0.0075$, satisfying roughness coefficient scale), while the downstream river bed is made with mobile sediment to satisfy "scouring similarity". Model discharge is measured by E-MAG, which is an electromagnetic flowmeter with high accuracy. The discharge capability, flow regime, hydraulic jump in the tunnel and the energy dissipation at the exit are mainly investigated under different hydraulic conditions. Note that, all the measured values from model in this paper are converted to the corresponding prototype values according to the above scaling parameters.

\section{EXPERIMENT RESULTS AND ANALYSIS}

\section{III.1. Discharge capability of the spillway tunnel}

As the gate of the spillway tunnel is fully open, the discharge capability gradually increases with the rising of the reservoir water level. The functional relationship between the water level and the discharge is shown in Fig. 2, based on measured data in the model.

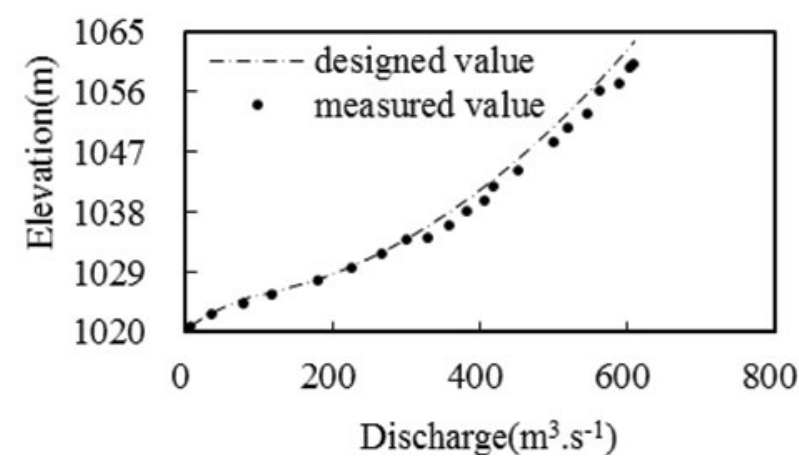

Figure 2 : Headroom ratio distribution along the tunnel. The headroom ratio is smaller where the water depth is larger. However, the headroom ratios throughout the tunnel are all above $20 \%$, satisfying the technical standard. 


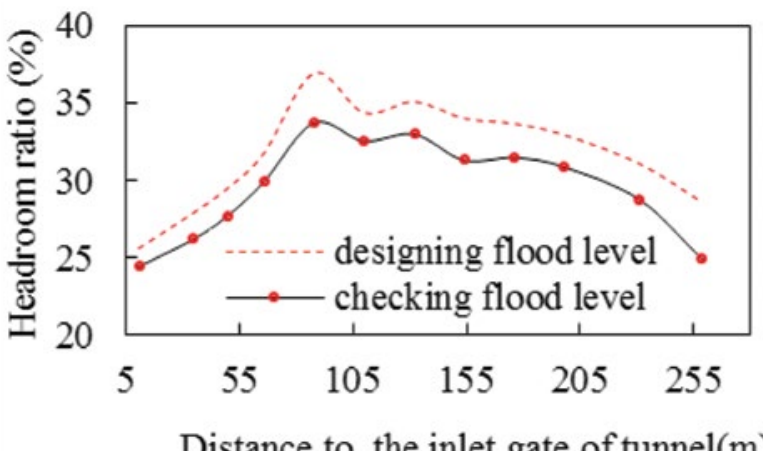

Figure 3 : Relationship of water level and flow discharge as predicted by $1 D$ hydraulic computation (designed values) and as measured in the physical model and scaled up (measured value).

\section{III.2. Flow regimes and energy dissipation effects during high discharge operations}

For the designing flood level and checking flood level, there is always a supercritical flow in the free surface flowing tunnel. The velocity ranges in $20-30 \mathrm{~m} / \mathrm{s}$, and the depth is about in 4.2-5.0 m (Froude's number $F r=3.13-4.28$ ). Taking the high velocity flow into account, the headroom ratio along the tunnel is shown in Fig.3. Headroom ratio denotes the ratio of the cross-sectional area of the headroom to that of the tunnel. Fig. 3 shows the changing character of headroom ratio along the tunnel. The operation of the tunnel is obviously safe during the large flood period, because the headroom ratio is more than $24 \%$ and satisfies the request of Design specification for the spillway tunnel.

During both the designing flood and the checking flood period, we observe a ski jump flow [Heller, et al., 2005] developing over the flip bucket, which is very strong and is up to $50 \mathrm{~m}$ in jump length, and $7 \mathrm{~m}$ in height, along the tunnel axis approximately. Ski jump flow means that the flow is deflected upward as depicted in Fig.4(a). The impingement of the ski-jump flow on the free surface generates a longitudinal stretched fluctuating region in the downstream river reach, shown in Fig.4(a, b). Then surging wave, up to $2.3 \mathrm{~m}$ high, occurs in the opposite right bank, which brings the strong recirculation current near the right bank and the scours fending dike. The maximum scouring depth ranges in $7 \mathrm{~m}-9 \mathrm{~m}$ along the right bank, shown in Fig.4(b).

\section{III.3. Hydraulic characteristics and potential tunnel choking risk during specific discharging operations}

During the operation of the tunnel, the flow is subcritical and stable in the tunnel when the reservoir water level is low, in the range of $1020 \mathrm{~m}$ and $1025 \mathrm{~m}$. The flow in the tunnel is supercritical when the water level is high and in the range of $1035 \mathrm{~m}$ and $1063 \mathrm{~m}$. The maximum water depth is $5.40 \mathrm{~m}$ and the flow is also quite stable. However, when the water level is in the range of $1026 \mathrm{~m}$ and $1035 \mathrm{~m}$, the upper flow in the tunnel is supercritical while the downstream flow is subcritical, resulting in a moving hydraulic jump. The hydraulic jump locations and sequent depths are recorded while rising the reservoir water level, which contributes to push the hydraulic jump downstream. The hydraulic jump will move out of the tunnel when the reservoir water level is over $1035 \mathrm{~m}$, and it will leave the deflecting flow section when the water level is over $1038 \mathrm{~m}$. When the reservoir water level is $1030 \mathrm{~m}$, the hydraulic jump moves close to the outlet section of the tunnel whereas the jump height is maximum level. In such conditions, the depth after the hydraulic jump reaches $7.85 \mathrm{~m}$ which surpasses the maximum height of $7.45 \mathrm{~m}$, and forces the tunnel to flow full in pressure. In Fig 5 the tunnel

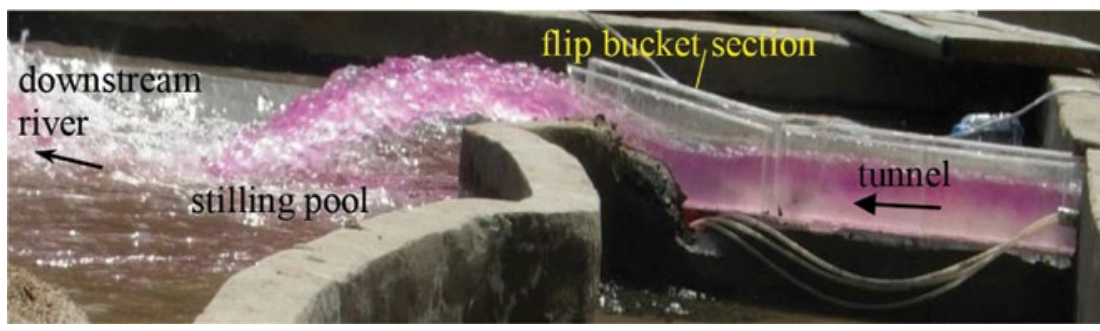

(a) Flow regime in the tunnel and flip bucket section

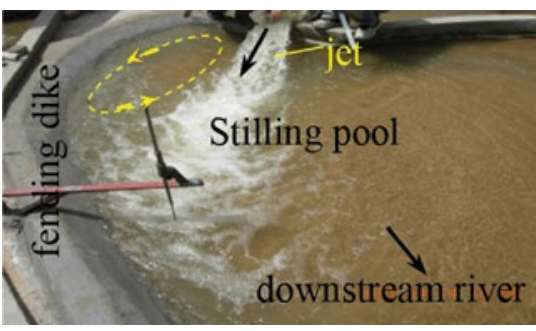

(b) Flow regime in downstream river

Figure 4 : Flow regime in the spillway tunnel and downstream river. Panel (a) shows a strong ski jump flow occurring at the exit of the flip bucket section under design flood level; in such conditions the headroom in the tunnel corresponding to the supercritical flow meets the design requirement. Panel (b) shows the jet directly towards the right fending dike, causing strong surge waves and circulation current.

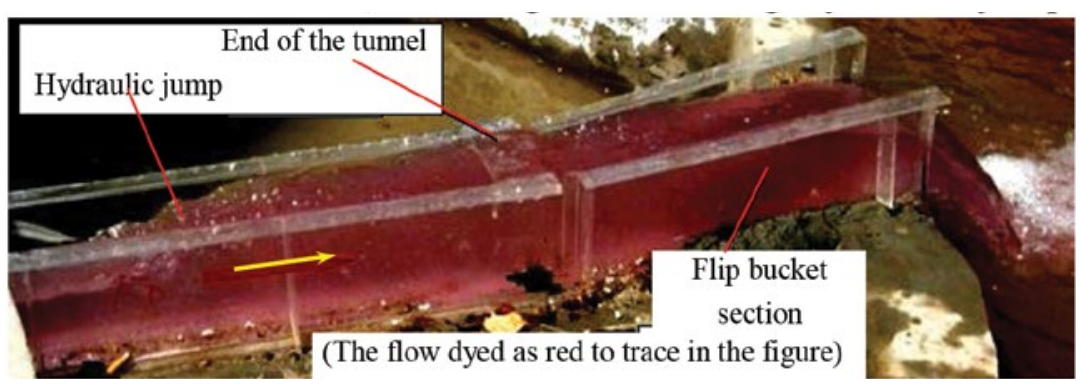

Figure 5 : : Hydraulic jump in the tunnel, close to choking conditions. When the tunnel is operated at lower water level, corresponding to lower discharge, the hydraulic jump occurs near the exit section, which leads to an excessively large downstream water depth in the subcritical flow reach of the tunnel, causing the choking. For this reason headroom ratios lower than $20 \%$ will endanger the operation safety of tunnel. 
Table 2 : Froude number and water depth before the hydraulic jump for varying water levels

\begin{tabular}{|c|c|c|c|c|c|c|c|c|c|c|}
\hline Water level $(\mathrm{m})$ & 1026 & 1027 & 1028 & 1029 & 1030 & 1031 & 1032 & 1033 & 1034 & 1035 \\
\hline$Q\left(\mathrm{~m}^{3} . \mathrm{s}^{-1}\right)$ & 136.5 & 149.1 & 169.5 & 200.3 & 207.1 & 240.8 & 265.6 & 281.1 & 295.3 & 311.6 \\
\hline$h^{\prime}(\mathrm{m})$ & 3.474 & 2.947 & 2.990 & 3.011 & 2.654 & 3.385 & 3.981 & 4.385 & 4.872 & 6.009 \\
\hline$F r_{1}$ & 1.111 & 1.553 & 1.728 & 2.021 & 2.524 & 2.038 & 1.762 & 1.613 & 1.447 & 1.115 \\
\hline Notes: & \multicolumn{1}{|c}{ and $F r_{1}$ are the depth and Froude number before hydraulic jump respectively } \\
\hline
\end{tabular}

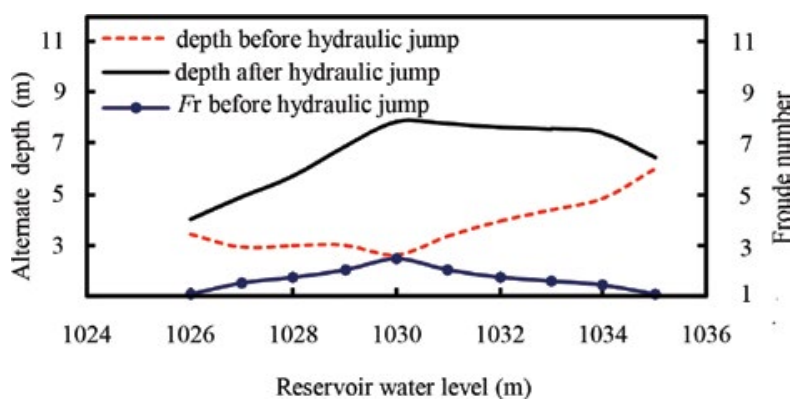

Figure 6 : Relationship among water level, alternate depths and supercritical Froude number Frl before the hydraulic jump. The reservoir water level corresponding to the strongest jump and maximum depth after the jump is indicated ast $1030 \mathrm{~m}$.

model lid was removed to show the hydraulic jump just before approaching the choking conditions.

When the reservoir water level increases along with the flow velocity in the tunnel, the hydraulic jump intensity and the depth after jump show a tendency of increasing first gradually and then decreasing. The maximum $\mathrm{Fr}_{1}$ (upstream of the hydraulic jump) is 2.52 corresponding to the maximum water depth downstream of the hydraulic jump. $F r_{1}$ is given as $F r_{1}=v / \sqrt{g h_{m}}$, where $h_{\mathrm{m}}$ denotes the maximum water depth. Changes of $F r_{1}$ and alternate flow depth at different reservoir water levels are shown in Fig. 6 and Table 2.

From Fig. 6 and Table 2, it can be seen that the hydraulic jumps causing the tunnel choking occur in the tunnel when the reservoir water level reaches $1026 \mathrm{~m}$ (water head $H=6 \mathrm{~m}$ ). With water level increasing further, the jump intensity enlarges gradually. The jump intensity is the largest when water level reaches $1030 \mathrm{~m}$, i.e., water head $H=10 \mathrm{~m}$. The water depth after the hydraulic jump is over the side wall height of the tunnel when water level is over $1027.5 \mathrm{~m}$. The tunnel is flowing full, in pressure, when water level is above $1029.5 \mathrm{~m}$. Consequently, the water depth in the tunnel is beyond the technical specs of headroom ratio ensuring free surface operating conditions when the water level ranges from $1027.5 \mathrm{~m}$ to $1035 \mathrm{~m}$, i.e., water head $H=7.5 \mathrm{~m} \sim 15 \mathrm{~m}$.

In general, when the $\mathrm{Fr}$ is over 3.0 in the open tunnel, the possibility for occurring hydraulic jump is little. So, the reservoir manager should be careful to avoid the risk of hydraulic jump in tunnel, when $\mathrm{Fr}$ of the free surface flow in the tunnel ranges in 1.5-3.0, at discharging period corresponding to relative water head $H / H d=0.18 \sim 0.37$. $H d$ denotes the water head corresponding to design flood discharge.

There are two main reasons contributing to the hydraulic jump occurring in tunnel, one is the small discharge with low water level in transient periods, and the other is the low drop between inlet and outlet of the spillway tunnel. As a result, the flow conditions in the flip bucket section are definitely different from those upstream of the bucket. The water depth of the flip bucket section is higher and the flow regime is subcritical. However, the water depth upstream of the bucket is lower and the flow regime is supercritical owing to the $1 \%$ steep slope of the tunnel. The hydraulic jump will occur undoubtedly at the transition section between the subcritical flow and supercritical flow in the tunnel. As the water depth in the tunnel changes with varying discharge, the transition section varies as well. Therefore, the occurrence and physical location of the hydraulic jump is also unstable, and the hydraulic jump may move up and down along the tunnel with the discharge changing.

The appearance of the hydraulic jump could be connected with the specific momentum values in front of flip bucket, this relevance can be expressed as function of water depth and discharge based on the conjugate equations of hydraulic jump, shown as follows.

$$
h^{\prime \prime}=\frac{h^{\prime}}{2}\left(\sqrt{1+8 \frac{q^{2}}{g h^{\prime 3}}}-1\right)
$$

Where, $h^{\prime \prime}$ is the water depth after the jump, $q$ is the discharge per unit width. $h^{\prime}$ is the water depth before jump i.e., the water depth at the downstream tunnel section where the flow is approximately uniform, providing the length of tunnel is not too short.

Thus, $h^{\prime}$ can be obtained by Manning-Strickler formula approximately, shown as follow:

$$
\begin{gathered}
V=\frac{1}{n} R^{2 / 3} S^{1 / 2} \\
q=V h^{\prime}
\end{gathered}
$$

Then, $q=\frac{1}{n} R^{2 / 3} S^{1 / 2} h^{\prime}$

$V$ denotes the mean flow velocity. $S$ denots the slope of the energy line. $b$ is defined as the ratio of the width $B$ to water depth before the jump, $h^{\prime}$. $\left(\beta=B / h^{\prime}\right)$. The hydraulic radius $R$ for channel with rectangle section can be given as $R=\beta h^{\prime} /(\beta+2)$. So, $q=n^{-1}[\beta /(\beta+2)]^{2 / 3} h^{5 / 3} S^{1 / 2}$, and $h^{\prime}$ can be expressed as

$$
h^{\prime}=q^{3 / 5}\left[\frac{n}{S^{1 / 2}}\left(\frac{\beta+2}{\beta}\right)^{2 / 3}\right]^{3 / 5}=\eta q^{3 / 5}
$$

Where $\eta$ is defined as $\eta=\frac{n^{3 / 5}}{S^{3 / 10}}\left(\frac{\beta+2}{\beta}\right)^{2 / 5}$

Here, $\eta$ denotes the character coefficient of the tunnel, and it is only related to the slope of the energy line $S$, the roughness coefficient $n$ and the ratio width to depth $\beta$ of the tunnel.

When the water depth at the beginning of the flip bucket, $D_{1}$, is equal to the critical depth $h_{\mathrm{k}}$ the ski jump flow is not sustained any more under supercritical conditions, and the 
hydraulic jump will form. $h_{\mathrm{k}}$ can be estimated by the following equation.

$$
h_{\mathrm{k}}=\sqrt[3]{\frac{q^{2}}{g}}
$$

When the hydraulic jump just occurs under the critical condition, the water depth $h^{\prime \prime}$ in front of bucket can be expressed as follows.

$$
h^{\prime \prime}=P+h_{\mathrm{k}}=P+\sqrt[3]{\frac{q^{2}}{g}}
$$

Where, $P$ is the height of the flip bucket.

Combined with Formula (8), Formula (10) and Formula (13), the critical conditions at which the hydraulic jump just starts appearing in the flip bucket can be predicted as follows.

$$
P+\frac{q_{\mathrm{c}}^{2 / 3}}{g^{1 / 3}}=\frac{\eta q_{\mathrm{c}}^{3 / 5}}{2}\left(\sqrt{1+\frac{8 q_{\mathrm{c}}^{1 / 5}}{\eta^{3} g}}-1\right)
$$

The discharge in Formula (14) is called as critical discharge $q_{\mathfrak{c}}$, which is the minimum discharge that starts generating the ski jump flow.

When unit discharge $q$ is larger than $q_{\mathrm{c}}$, the flow momentum is big enough to sustain the ski jump flow over the flip bucket, and the flow along the whole tunnel is all supercritical flow. However, when the $q$ is less than $q_{\mathrm{c}}$, the flow at the bucket hasn't enough momentum to form the ski jump, and the backwater effect will occur, causing the appearance of the hydraulic jump in front of the flip bucket. In such condition, the flow regime before the hydraulic jump is all supercritical and after the jump is subcritical. The appearance position and the intensity of hydraulic jump are all related with the water depth and the flow momentum at the flip bucket section, and both of them can be predicted by 1-D hydraulic computations based on jump conjugate equations.

When the discharge isn't large enough to supply enough momentum to form the supercritical ski jump flow, the hydraulic jump will occur in the tunnel. At this critical point, the critical discharge $q_{c}$ can be calculated by 1D hydraulic analytical computation formula (14) as $q_{\mathrm{c}}=0.485 q_{\mathrm{d}}$, $H_{\mathrm{c}}=0.382 H_{\mathrm{d}}$, where, $q_{\mathrm{d}}$ denotes the design flood unit discharge, and $H_{\mathrm{d}}$ denotes the water head corresponding to $q_{\mathrm{d}}$. However, due to effect of backwater curve in the tunnel and the complexity of the boundary conditions, the critical value measured in model experiment is about $q_{\mathrm{c}}=0.479 q_{\mathrm{d}}$, $H_{\mathrm{c}}=0.37 H_{\mathrm{d}}$, which shows little discrepancy with the analytical computation. Based on this, it is important to measure also the position of the hydraulic jump in the model experiment, which is more reliable than the analytical computation.

Therefore, in order to avoid the tunnel choking in transiting periods of discharge, engineering modification must be introduced to decrease the water depth at the tunnel exit and to mitigate the hydraulic jump intensity.

\section{MODIFICATION MEASURES AND EXPERIMENT RESULTS}

\section{IV.1. Possible solutions and site-specific limitations}

Limited by geographical conditions at the tunnel exit, the low drop tunnel reach cannot be changed. Consequently, adjusting the flip bucket design downstream of the tunnel outlet becomes the only approach to solve the tunnel choking caused by the hydraulic jump. Attempts of different modifications tested through model experiments show that it is difficult to i) ensure a powerful ski jump flow over the flip bucket to achieve the desired energy dissipation requiring a significant deflecting angle, and ii) avoid the hydraulic jump in the tunnel by decreasing flip bucket elevation. Indeed, reducing the height of the flip bucket without adjusting the direction of the ski jump flow, would not dissipate enough energy. That's because the water level in the stilling pool is only $2.5 \sim 3.5 \mathrm{~m}$ lower than the elevation of the flip bucket structure. Experiment also indicates that, surging waves, caused by the jet resulting from the ski jump flow, induce a strong scour at the right fending dike in the downstream river; this is mostly due to the angle $\left(b \approx 30^{\circ}\right)$ between the flip bucket center line (tunnel axis) and the downstream direction of the river, as illustrated in Fig.7. Comparing the flow regime in the modified scheme and in the original design, indicates that it is necessary to adjust the angle of the ski jump flow direction appropriately to weaken the surging wave and the scouring at the fending dike.

Based on the above considerations, the problems of the original design can be solved as it follows: (1) adopting a skewed bottom and a torsion angle in the flip bucket section to adjust the ski jump flow direction, and to avoid the strong wave and scouring towards the right dike downstream; (2) setting up a side weir in the bending deflecting section to split the flow, through an ingenious use of the centrifugal force acting on the ski jump flow, to avoid strong hydraulic jump occurring in the tunnel. Detailed modification plans are given in Fig.8. Note that, the spillway down the side weir is needed, see the side weir spillway in Fig.9.

Firstly, deflecting flow section in original design is replaced by a curved channel with skewed bottom which runs out left with a torsion angle of $32^{\circ}$, see Fig. 8 (a), (b). Then a side weir is set up, connected with the left side wall at the joint between the tunnel outlet and the deflecting flow section. The shape and size of the side weir are given in Fig. 8. The cross section of the side weir is right angle trapezoid; its bottom elevation is $1017.68 \mathrm{~m}$ and width is $4.18 \mathrm{~m}$. The side weir hypotenuse is a triangle shaped guide wall with an angle of $27^{\circ}$, see Fig.8(c). Such triangular wall is designed to avoid flow spilling out of the side weir.

\section{IV.2. Performances and evaluation of the modified project}

After reconfiguring the exit section, new experiment were performed and the results show the evident effect of

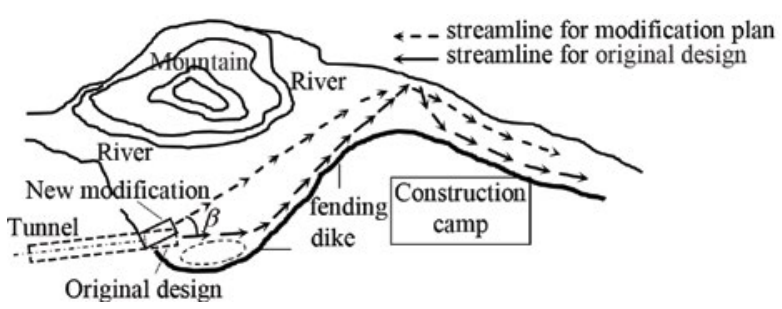

Figure 7 : Comparison of the ski jump flow direction out of the tunnel and into the downstream river between the two schemes. The original designed ski jump flow direction in the exit section was inconsistent with the river mainstream, which causes a return current near the right bank and explains the scouring against the fending dike. The modified scheme revises the ski jump flow direction, and makes it consistent with the river direction. The flow is regulated and the surging wave disappears. 


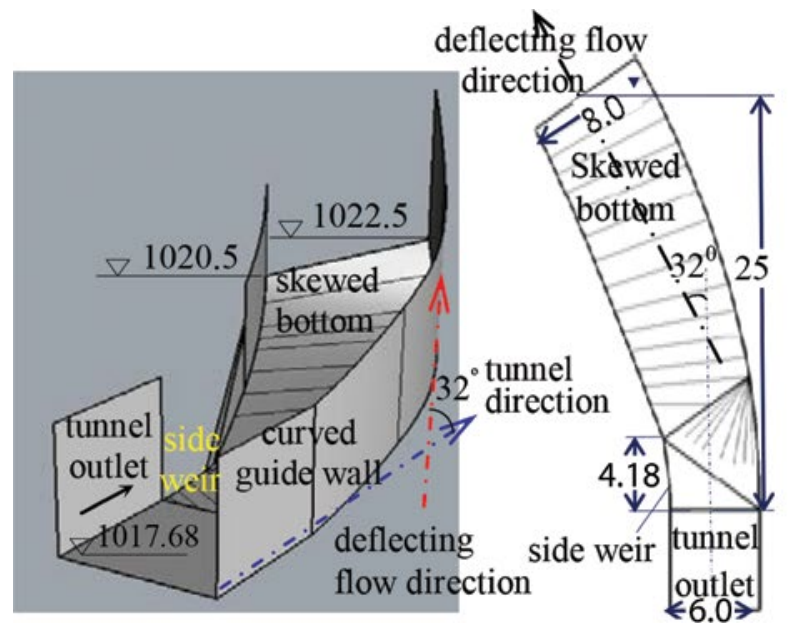

(a) Front view from the tunnel upstream (b) Top view
Unit: $\mathrm{m}$

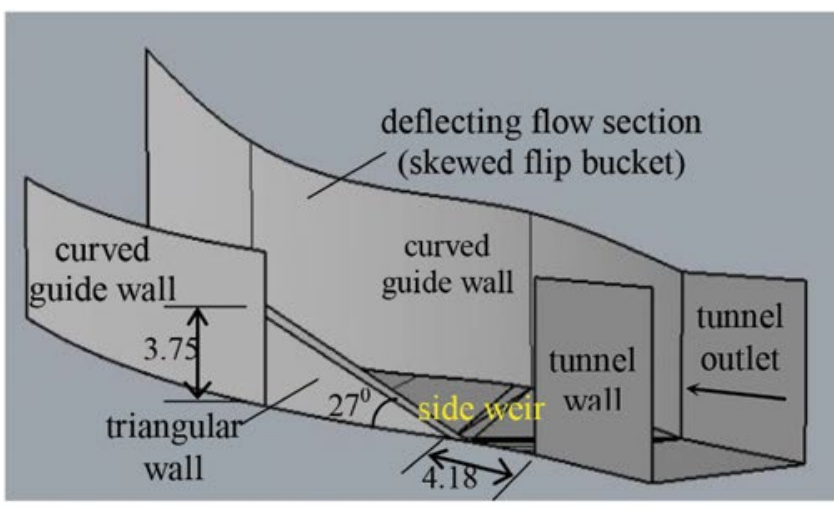

(c) Side view

Figure 8 : Three-dimensional model of the skewed flip bucket in the modified scheme. The location, shape and size of the torsion angle, the skewed bottom, the curved guide and triangular walls, the side weir design, the direction of the guide wall and the deflecting flow direction are introduced.

the hydraulic structure modification. When the reservoir water level is low, the flow in the tunnel is shallow and the discharge of the flow through the side weir is dominant in the deflecting flow section, while the discharge through the flip bucket is less than $10 \%$. When the water level reaches $1022 \mathrm{~m}$, a weak hydraulic jump occurs and its position is defined by $h=0.21$ (where, $h=x / L, x$ is the distance between hydraulic jump and tunnel inlet, $L$ is total length of the tunnel). When the water level reaches $1024 \mathrm{~m}$, the hydraulic jump reaches the position $h=0.82$, where the depth before the hydraulic jump is $1.38 \mathrm{~m}$ and the depth after the hydraulic jump is $3.03 \mathrm{~m}$. These two conditions have no influence on the free surface flow in the tunnel. At this period, discharge through the side weir (about 60\%-80\%) is larger than the discharge through the flip bucket. With the increase of reservoir water level, the hydraulic jump continues to move forward. Meanwhile, due to the depth and discharge reduction caused by the side weir, the depth after the hydraulic jump is also reduced and the phenomenon of tunnel choking is avoided. When the water level is $1028 \mathrm{~m}$, hydraulic jump leaves the tunnel. At this moment, the discharge through the side weir is minimal as compared to the discharge through the flip bucket. When water levels

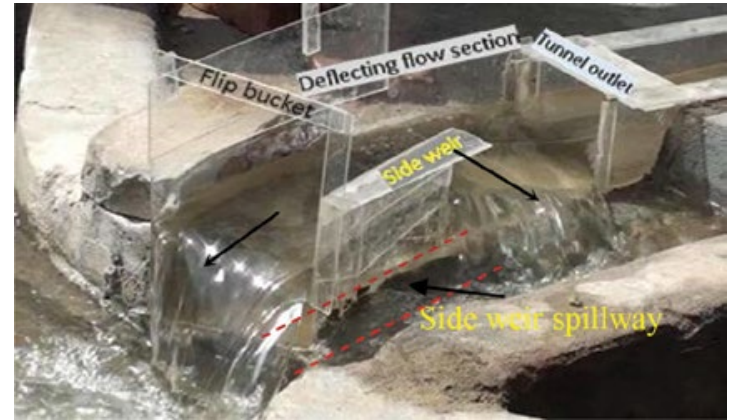

(a) Water level is $1035 \mathrm{~m}$ are in the range from $1022 \mathrm{~m}$ and $1035 \mathrm{~m}$, the flow regimes at the flip bucket and at the side weir are given in Fig. 9.

With increasing water level, the ski jump flow strengthens and the discharge through the flip bucket increases gradually. Meanwhile, due to the effect of the centrifugal force in the curved section, the discharge through the side weir keeps decreasing gradually. When the water level is higher than $1038 \mathrm{~m}$, the hydraulic jump is pushed outside the flip bucket and the ski jump flow is formed, whereas the flow in the whole tunnel stays supercritical. When the water level is higher than $1056 \mathrm{~m}$, the centrifugal force makes the flow discharge through the side weir almost negligible. At the checking flood level, there is no water passing through the side weir. Water depth at the left side of the flip bucket is about $3.58 \mathrm{~m}$, and depth of the right is about $6.3 \mathrm{~m}$. The Flow regime in this configuration is shown in Fig. 10. The split-flow ratio of the side weir is defined as $h_{1}=Q_{\mathrm{s}} / Q_{\mathrm{t}}$, and the split-flow ratio of the flip bucket is defined as $h_{2}=Q_{\mathrm{f}} /$ $Q_{\mathrm{t}}$, where, $Q_{\mathrm{s}}$ and $Q_{\mathrm{f}}$ denote the discharge through side weir and flip bucket, respectively, and $Q_{\mathrm{t}}$ represents the total discharge. Interdependent relationships among $\eta_{1}, \eta_{2}$ and reservoir water levels are given in Fig. 11.

When the water level is between $1021 \mathrm{~m}$ and $1027 \mathrm{~m}$, there is still a weak hydraulic jump in the tunnel accompanied with

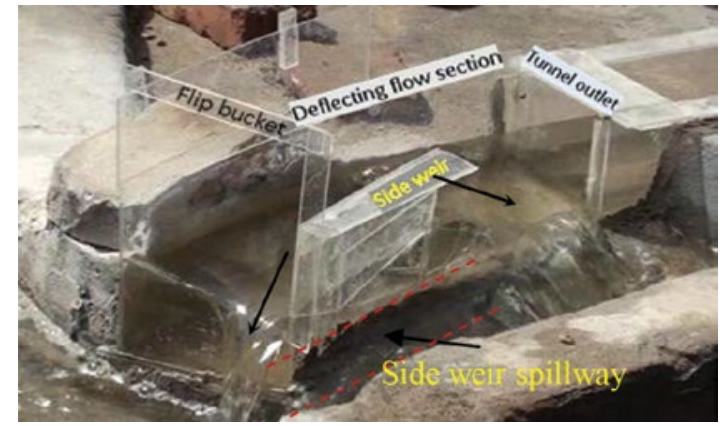

(b) Water level is $1022 \mathrm{~m}$

Figure 9 : Comparison on the discharge of the flow separated by the side weir between different water levels. The ratio of the flow separated by the side weir is variable while the reservoir water level is decreasing. Panel (a) indicates the discharge of the flow through the side weir is about the same of the flip bucket when the water level is high. Panel (b) shows the flow separated by the side weir is much more than the one through the flip bucket when the water level is low. 


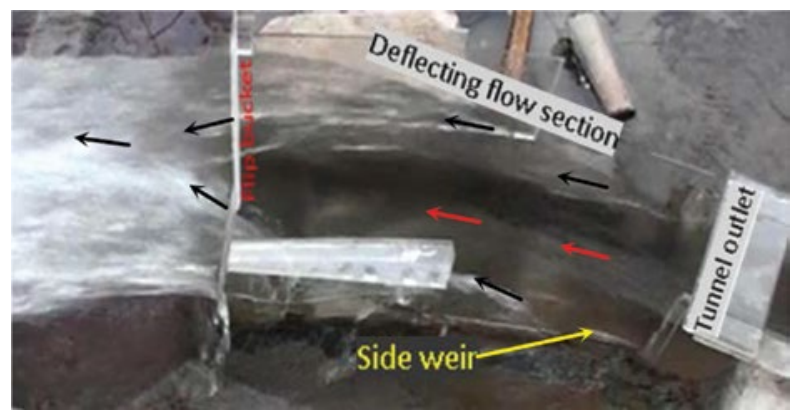

Figure 10 : Ski jump flow through the flip bucket section at design flood level. There is no flow through the side weir when the water level is high (design flood level), and the ski jump flow over the bucket flip is strong.

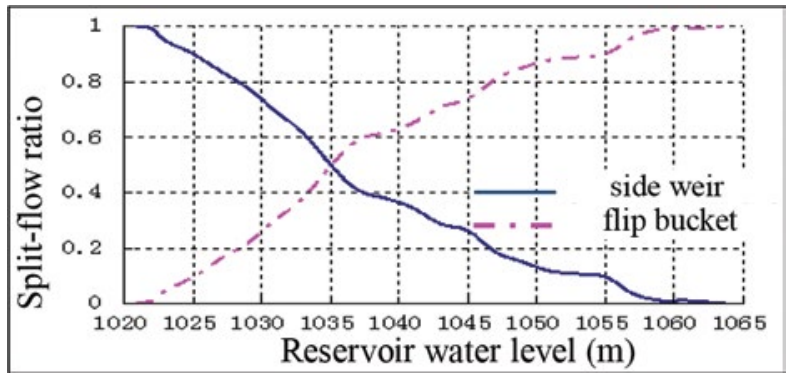

Figure 11 : Split-flow ratio at different water levels. As a result of the centrifugal force, the split-flow ratio of the side weir is very small at high water levels, and very large at low levels.

a quite small depth after the hydraulic jump. When the water level reaches $1028 \mathrm{~m}$, the hydraulic jump disappears. With a further increase of reservoir water level, the water depth in the tunnel increases accordingly. At the checking flood level, the maximum water depth along the tunnel is less than $5.3 \mathrm{~m}$, with the headroom meeting the requirement of safe discharging in the tunnel. The maximum water depth in the deflected flow section is $6.3 \mathrm{~m}$, which is also less than the height of the side wall and thus remains in the safe range. A fending dike, is designed at the side of the stilling pool downstream of the side weir spillway outlet to prevent bed scouring (the position of side weir spillway is shown in Fig. 9). Because the maximum unit discharge through the side weir is less than $7.8 \mathrm{~m}^{2} / \mathrm{s}$ and the velocity of the flow entering the stilling pool is less than $4 \mathrm{~m} / \mathrm{s}$, which is lower than the scouring velocity of the revetment, it will not cause any damage.

In conclusion, adding the side weir has no influence on the discharging operations of the reservoir at the design and checking flood water levels. Even though there is a weak hydraulic jump in the tunnel when the reservoir water level is low, the depth after the hydraulic jump is quite small and meets the headroom requirement for discharging in the tunnel. When the water level is $1028 \mathrm{~m}$, a weak hydraulic jump is pushed outside the tunnel and it disappears soon, which solves the phenomenon of tunnel choking. In addition, setting a $32^{\circ}$ torsion angle makes the direction of the ski jump flow parallel with the downstream channel, and alleviates the opposite surging wave and scouring of the dike. The experiment measured data indicates that the surging wave decreases to $0.3-0.5 \mathrm{~m}$, and the scouring depth decreases to $3-4 \mathrm{~m}$ along the right bank. Due to the effect of energy dissipation in the downstream channel, the river regime is relatively smoother, as shown in Fig.7.

\section{CONCLUSIONS}

Based on the experimental study on reservoir discharging through a low drop, free surface flowing, tunnel, some valuable conclusions are presented and discussed, and some structural modifications are suggested.

With the original design of the spillway tunnel, when the reservoir water level is low, the flow in the tunnel is subcritical and the flow regime is stable. When the water level is relatively high, the flow in the tunnel is supercritical and the flow regime is also stable. However, during the discharging transient process, a hydraulic jump may occur and move in the tunnel for a specific range of reservoir water levels. The hydraulic jump mainly occurs in the low drop tunnel when the reservoir water level is relatively low. With increasing water levels, the hydraulic jump is observed to increase its intensity and be pushed outside of the tunnel. However, when the hydraulic jump is in the tunnel, the depth in the subcritical flow downstream of the hydraulic jump is relatively high and in some conditions can choke the tunnel cross section causing operational risks by flowing full, as a pipe in pressure.

Based on the experimental results obtained in our physical model, we conclude that the probability of hydraulic jump is small, when the $F r$ is over 3.0 in the supercritical upstream tunnel reach. So, to avoid the potential risk caused by the hydraulic jump in the tunnel, the reservoir manager should be careful when $F \mathrm{r}$ in tunnel ranges 1.5-3.0 during discharging operations, corresponding to relative water head $H$ / $H_{\mathrm{d}}=0.18 \sim 0.37$. Based on 1D hydraulic conjugate under uniform flow approximation, a critical discharge is estimated as $q_{\mathrm{c}}=0.485 q_{\mathrm{d}}$, below which the ski jump flow disappears and the hydraulic jump appears. Such limiting conditions well agrees with the experimentally observed value of $q_{\mathrm{c}}=0.479 q_{\mathrm{d}}$. However the occurrence of the jump does not necessarily cause the choking of the tunnel. Specifically, from experimental observations we also report that for $q<0.241 q_{\mathrm{d}}$ the hydraulic jump occurs but the water depth after the jump is not high enough to prevent free surface flow.

In order to eliminate the potential trouble caused by the hydraulic jump in the tunnel in the $0.241 q_{\mathrm{d}}<q<0.479 q_{\mathrm{d}}$ range and adjust the direction of the ski jump flow at the tunnel outlet, structural modifications of the original design are proposed: i) using a skewed bottom in the deflecting flow section, ii) turning the angle of the side wall to adjust the ski jump flow direction, iii) adding a side weir for splitting the flow in the convex side of the deflecting flow section to suppress or mitigate the hydraulic jump intensity.

Experiments in the modified configuration show that when the reservoir water level is quite low, the advantage of the side weir is evident; downstream water depth and hydraulic jump intensity are suppressed effectively; safe operation of the tunnel at transitional discharging period is guaranteed. When the reservoir water level is relatively high, side weir is progressively bypassed due to the effect of the centrifugal force along the deflecting flow sections, and the ski jump flow over the curved flip bucket is fully developed, ensuring the required energy dissipation. The ski jump angle is also adjusted and the downstream flow regime is improved, limiting potential erosion in the river.

\section{ACKNOWLEGMENTS AND THANKS}

The financial supports of the National Natural Science Foundation of China (Grant No. 51579206 and Grant 
No. 51579013) and the Natural Science Basic Research Plan in Shaanxi Province of China (Grant No. 2015JM5201) are gratefully acknowledged. The first author received a fellowship from the China Scholarship Council.

\section{REFERENCES}

Chanson H. (2011) - Momentum considerations in hydraulic jumps and bores. Journal of Irrigation and Drainage Engineering, 138(4), 382-385.

Chen S., WANG J.X. (2013) - Experimental study on Kolmogorov's length scale in hydraulic jumps of low Froude numbers. Journal of Hydroelectric Engineering, 32(2), 179-183.

CHow V. T. (1959) - Open-channel hydraulics, New York: McGrawHill Book Company.

FAN L., Zhang H.W., \& LiU Z.P. (2009) - Numerical study on hydraulic characteristic of free surface flow in spillway tunnel with different configuration. Journal of Hydroelectric Engineering, 28(3), 130-137.

Heller V., Hager W.H., Minor H.E. (2005) - Ski jump Hydraulics. Journal of Hydraulic Engineering, 131(5), 347-355.

JAN C.D., ChANG C.J. (2009) - Hydraulic jumps in an inclined rectangular chute contraction. Journal of Hydraulic Engineering, 135(11), 949-958.

JUON R., HAGER W.H. (2000) - Flip Bucket without and with deflectors. Journal of Hydraulic Engineering, 126(11), 837-845.
LENNON J.M., HiLl D.F. (2006) - Particle image velocity measurements of undular and hydraulic jump. Journal of Hydraulic Engineering, 132(12), 1283-1294.

LEUTHEUSSER H.J., KARTHA V.C. (1972) - Effects of inflow condition on hydraulic jump. Journal of the Hydraulics Division, 98(8), 1367-1385.

MA X.D., DAI G.Q., YANG Q., Et Al. (2012) - Effect of aerated jet on hydraulic characteristics of spillway tunnel side-wall with abrupt lateral expansion and bottom offset aerator. Journal of Hydroelectric Engineering, 31(3), 142-147.

Sun D.P., Cao S., Song Y.J. ET Al. (2013) - Experimental research on improving the trajectory energy dissipation effectiveness of spillway tunnel. Journal of North China Institute of Water Conservancy and Hydroelectric Power, 34(6), 8-11.

Politano M., Odgaard A.J., Klecan W. (2007) - Case study: Numerical evaluation of hydraulic transients in a combined sewer overflow tunnel system. Journal of Hydraulic Engineering, 133(10), 1103-1110.

U. S. Army Engineer Waterways Experiment Station, Corps OF ENGINEERS. (1977) - Hydraulic design criteria, Vicksburg, Miss, (2), 115-117.

Wright S.J., Lewis J.W., And Vasconcelos J.G. (2010) Geysering in rapidly filling storm-water tunnels. Journal of Hydraulic Engineering, 137(1), 112-115.

Wu X.Y., Sun D.P. (2014) - Study on impact from skew bucket on trajectory bucket energy dissipation for flood discharge tunnel. Water Resources and Hydropower Engineering, 45(8), 56-60.

YALIN M.S. (1971) - Theory of hydraulic models. London: Macmillan Education UK. 